\title{
Interannual variation in tree seed production in a primeval temperate forest: does masting prevail?
}

\author{
Tomasz Wesołowski • Patryk Rowiński • \\ Marta Maziarz
}

Received: 23 March 2014/Revised: 26 July 2014 / Accepted: 30 July 2014/Published online: 14 August 2014

(C) The Author(s) 2014. This article is published with open access at Springerlink.com

\begin{abstract}
We assessed seed production by mature individuals of five dominant tree species in the strictly protected reserve of Białowieża National Park (Poland) from 2002 to 2013. Interannual variation in seed production was extreme, generally asynchronous among species. All species exhibited high variability in seed production, ranging from bumper crops in some years to no seeds in others. All species exhibited a typical "normal masting" pattern, which was most pronounced in Picea abies and Quercus robur, moderate in Carpinus betulus and least expressed in Acer platanoides and Tilia cordata. Within species, crop sizes were well synchronised among areas and individuals; seed production was most synchronised in $P$. abies and $Q$. robur and least synchronised in $T$. cordata and A. platanoides within a season. Among species, interannual variability was negatively correlated with seasonal synchrony among individuals. Besides a negative correlation between rainfall during the flowering period and seed crop in three deciduous species, variation in temperature and rainfall in periods critical to seed formation was uncorrelated with the variation in seed crops. Heavy defoliation by caterpillars coincided with a poor seed crop of deciduous trees in 2003. Generally, the variation in seed crops was much higher than the variability of environmental factors. Deciduous
\end{abstract}

Communicated by Christian Ammer.

T. Wesołowski $(\bowtie) \cdot$ M. Maziarz

Laboratory of Forest Biology, Wrocław University,

Sienkiewicza 21, 50335 Wrocław, Poland

e-mail: tomwes@biol.uni.wroc.pl

P. Rowiński

Department of Forest Zoology and Wildlife Management, Warsaw University of Life Sciences-SGGW, Nowoursynowska 159, 02776 Warsaw, Poland species could produce bumper crops in consecutive years and were not necessarily forced to "switch" to nonreproduction by resource depletion. It appears that trees could apparently assess when and how intensively to reproduce. We discuss adaptive benefits of masting reproduction that include pollination efficiency, predator satiation and seed dispersal.

Keywords Reproductive trade-off - Economy of scale . Resource matching · Environmental disruption . Oak-hornbeam forest

\section{Introduction}

Understanding patterns and mechanisms of variation in seed production of forest trees is essential in explaining numerous biological phenomena such as life history evolution, vegetation dynamics, plant-animal interactions, nutrient cycling or trophic cascades (Herrera et al. 1998; Zackrisson et al. 1999; Lugo and Zimmerman 2000; Thomas and Packham 2007; Yang et al. 2008). Determining patterns of seed production is also of immense value in forest conservation and management; a large and reliable supply of viable seeds is required for tree planting and forest regeneration (reviews in Matthews 1963; Owens 1995; Vozzo 2000).

Forest trees can exhibit highly variable seed production, ranging from no seeds in some seasons to extremely high seed production in others. This variation is often highly synchronised among individuals in a local population and even among different tree species in the same forest (e.g. dipterocarp forests, review in Appanah 1993). Such patterns of intermittent, synchronous, population-wide, mass production of seeds are termed "masting" or "mast seeding" (review in Kelly 1994). 
If there are only seeding (mast) and non-seeding years in a population ("strict masting", Kelly 1994), it is straightforward to classify them as "masting" and "non-masting" years, respectively. If, however, seed crops are highly variable among years, but there are years with intermediate production ("normal masting", Kelly 1994), it can be difficult, if not impossible, to define mast and non-mast years unequivocally. It is arguable how much variation between years and individuals defines seed production as "masting", should "masting" become a synonym of "annually variable seed production" or should it describe a narrower range of phenomena?

Several authors have attempted to find quantitative criteria for defining masting years and species (reviews Kelly 1994; Herrera et al. 1998; Koenig and Knops 2000; Crone et al. 2011), but most have failed to demonstrate the existence of clearly delimited "masting" groups. Variation tended to be continuous, with "masting" forming the extreme end of the distribution. Such results led (Herrera et al. 1998), on the one hand, to question the utility of the concept of "mast fruiting" in which they proposed discontinuing its use. On the other hand, Koenig and Knops (2000) advised retention of "masting" and "mast fruiting", even if the terms are not as distinct or well defined as may have been originally envisioned. They argue that the terms have utility, particularly as it pertains to focusing attention on this evolutionary significant and biologically intriguing phenomenon, because the extent of synchronisation and interannual variation in seed production may exceed that which can be explained by environmental variation alone. If seed output varies simply because extrinsic resources available to plants vary, and the trees produce seeds in direct proportion to available resources (the "resource matching" of Kleb 1904, in Norton and Kelly 1988), no additional evolutionary explanation is necessary. Even when resources are abundant, adverse environmental factor(s), e.g. destruction of blossoming flowers by a cold spell (e.g. Pigott and Huntley 1981; Kulagin and Mushinskaya 1984), can still prevent seed production and cause synchronous population-wide reproductive failures. If such events can be fully explained by these adverse external factors ("environmental disruption"), no additional mechanisms need be proposed.

If extrinsic environmental factors can fully explain pattern of seed production, no additional evolutionary explanation is needed (Koenig and Knops 2000). Masting would be invoked only when trees that are apparently able to produce seeds in benign conditions fail to do so. Thus, the existence of additional mechanisms that would allow trees to "decide" when and if to invest in intensive reproduction could be invoked. Considering the costs of mass seed production and the likelihood of physiological constraints of trees to reproduce in such a way (reviews
Kelly 1994; Herrera et al. 1998; Koenig and Knops 2000; Crone et al. 2011), there should be some selective advantage in producing large seed crops once in a few years rather than equal-sized smaller crops every year.

Various adaptive hypotheses have been offered to explain masting (review in Kelly 1994). The most common are related to the "economies of scale" (Norton and Kelly 1988): "if large episodes of reproduction are more efficient than the small ones, the plants would do better to produce occasional large episodes than regular ones". Likely mechanisms include seed predator satiation (Janzen 1971; Silvertown 1980) and more efficient wind pollination (Norton and Kelly 1988) or fruit dispersal; see reviews in Kelly (1994); Koenig et al. (1994); Herrera et al. (1998); Koenig and Knops (2000) and Kelly and Sork (2002).

To understand adaptive behaviours such as masting, one should study organisms in their evolutionary settings (e.g. Baker 1938; Lack 1965; Wesołowski 1983; Stutchbury and Morton 2001). Primeval forests provide an opportunity to observe forest ecosystems without anthropogenic influences.

Here, we examine the interannual variation in seed production and masting in five dominant tree species cooccurring in mixed stands in a primeval temperate forest within Białowieża National Park (BNP hereafter), Eastern Poland. We gathered 12 years of data on their annual fruit production and variation in environmental factors (2002-2013), free of direct human influence (strictly protected), old-growth portions of the BNP. The local trees are all of native origin, descendants of individuals that naturally colonised the area in post-glacial periods (Faliński 1986, 2001; Wesołowski 2007). Early studies in BNP (Falińska 1971; Pucek et al. 1993) demonstrated that seed production of different tree species strongly varied across years and that abundant crop years of deciduous species were followed by outbreaks of seed depredating rodents. In this study, we analyse patterns of inter-year variation in seed production by individual tree species in BNP, to examine to what extent different species adhere to masting predictions and whether such individuals could be arranged along a non-masting-masting axis. Following Koenig and Knops (2000), we expected that masting species should exhibit the following characteristics:

- variability in annual seed production. The frequency distribution of annual seed production in true masting species should be bimodal, and the coefficient of variation should be large. For strict masting species, there should be few, if any, years of intermediate seed production: in most years, the population should produce either very many or virtually no seeds.

- spatial autocorrelation. Annual seed production by true masting species should be synchronised with widely uniform environmental cues so as to maximise 
synchrony among individuals (Norton and Kelly 1988). Temperature and rainfall are likely environmental variables to be used as cues by forest trees.

- temporal autocorrelation. True masting species are predicted to transform resources from available reserves into seed production to produce large seed crops, leading to a negative correlation between seed production in a particular and subsequent year (Sork et al. 1993; Kelly 1994).

As masting is the result of reproductive "decisions" of individual trees in a local population, one has to study patterns of seed production and their synchrony at the individual level as well (Sork et al. 1993; Koenig et al. 2003; Herrera et al. 1998; Żywiec et al. 2012) in order to have a mechanistic understanding. Therefore, we also tracked performance of individual trees across years and analysed patterns of variation in their reproductive output among years.

Overall, we analyse individual- and population-level variation and synchrony of fruit production among five numerous tree species-Carpinus betulus L, Quercus robur L., Picea abies Karst, Tilia cordata Mill. and Acer platanoides L.-observed in different areas of BNP. Despite widely disparate phylogenetic origins all these species share basic features of their reproductive cycles, they form flower buds in a summer of one year and blossom in the spring of the following year and their fruits develop and mature within the year of pollination. They disperse pollen, though, by different means; $T$. cordata and Acer platanoides are insect-pollinated and the other species rely on wind. We test the extent to which the pattern of seed production can be explained by variation in abiotic (weather related) and biotic (defoliating caterpillars, pollination type) environmental factors. And, finally, we contrast the patterns recorded in BNP with predictions of masting-behaviour hypotheses (summarised in Kelly 1994; Koenig et al. 1994; Herrera et al. 1998; Koenig and Knops 2000; Kelly and Sork 2002).

\section{Study area and methods}

\section{Study area}

Situated on the Poland/Belarus border, the Białowieża Forest is located in a mixed forest zone, at the boundary of central and eastern Europe (the Białowieża village coordinates are: $52^{\circ} 41^{\prime} \mathrm{N}$ and $23^{\circ} 52^{\prime} \mathrm{E}$ ). Norway spruce Picea abies Karst. is a component of almost all types of stands (Faliński 1986). The primeval old-growth stands in the Białowieża Forest retain some features that are distinct among European temperate forests. They are multi-layered (up to 5-6 layers oak-lime-hornbeam Tilio-Carpinetum forest), with high age and size structure (up to 400-500 years old, reaching $52 \mathrm{~m}$ height and $740 \mathrm{~cm}$ circumference, Niechoda and Korbel 2011) and speciose. The oak-lime-hornbeam stands alone may be composed of a dozen or so tree species, including lime Tilia cordata Mill., pedunculate oak Quercus robur L., hornbeam Carpinus betulus L., maple Acer platanoides L., elms Ulmus spp., birches Betula spp., aspen Populus tremula L. and ash Fraxinus excelsior L. More details and photographs are given in Tomiałojć et al. (1984), Faliński $(1986,1991)$ and Tomiałojć and Wesołowski (1990, 2004).

The climate is subcontinental, with a mean annual precipitation of 624 (425-940) $\mathrm{mm}$, long-term average annual temperature of $+6.6^{\circ} \mathrm{C}$ and average January temperature of -4.8 ( -16.8 to 1.8 ) ${ }^{\circ} \mathrm{C}$. Snow cover (up to $95 \mathrm{~cm}$ deep) lasts up to 92 days; morning ground frost occurs as late as mid-May, even to mid-June (during the 1970s). Snow melt occurs between $\sim 10$ March (early) and 20 April (exceptionally late) — based on a 49-year time series (see Faliński 1986, 2001 and Jędrzejewska et al. 1997 for more information). Some warming was observed over the last 20-30 years (Wesołowski and Cholewa 2009), but temperatures have remained within the historic range already recorded during the previous warm period (1820-1870, Jędrzejewska et al. 1997).

\section{Data collection}

We gathered observations on tree seed crops in 2002-2013 in a diverse oak-lime-hornbeam Tilio-Carpinetum habitat. We recorded variation in seed production for the four most numerous deciduous species in this forest type: $C$. betulus, $T$. cordata, A. platanoides and $Q$. robur (which collectively accounted for over $90 \%$ of the deciduous trees, Wesołowski 1996), as well as in the only coniferous species present, $P$. abies. We conducted observations in three permanent study plots $(\mathrm{C}, \mathrm{M}$ and $\mathrm{W}, \sim 4 \mathrm{~km}$ apart, see map in Wesołowski 2012). Within each plot, ten groups of trees, at least $100 \mathrm{~m}$ apart, were selected. Each group consisted of one individual of every observed species, and trees grew close $(10-40 \mathrm{~m})$ to one another. These were all healthy trees, with crowns of a given species in the main canopy layer of the forest being examined. This way any possible microhabitat variation among sites would affect all species equally. The same groups of deciduous trees were used in observations of phenology of leaf development (plot W, Wesołowski and Rowiński 2006) and in studies of folivorous caterpillars (plots C and M, Maziarz and Wesołowski 2010). We assessed seed production of the same trees during the whole study (2002-2013). Trees that died during the study (mostly due to windfall: five $T$. cordata, four $Q$. robur, three $C$. betulus and one $A$. platanoides) were 
replaced by others of the same stature that grew nearest to the dead ones. In addition to the trees mentioned above, supplementary individuals were assessed for seed production each year. These trees were situated in between the permanent sample trees within the plots, as well as-in some seasons-in oak-hornbeam patches outside the plots. The total number of trees of a species scored within a season ranged from 53 to 310 per species.

Observations were carried out from 30 September to 6 November, after the majority of leaves had fallen, through binoculars or telescope, always by the same person (PR). Intensity of crop was scored on a five-point scale, ranging from 0 (no fruits) to 4 (heavy seed crop). To adjust for biological differences in fruit shedding pattern among the species, we scored the intensity of crop in a species-specific way:

- Acer platanoides, C. betulus and T. cordata-In these trees, the majority of infructescences were still hanging from twigs. Therefore, their numbers on apical $\sim 1-\mathrm{m}$ section of branches located in a southern upper part of the tree crown were counted. To account for premature shedding of some of the infructescences (e.g. by strong winds), remnant peduncles were also included. The results were classified as follows: no infructescences $=0,1-5=1,6-10=2,11-20=3$ and $>20$ infructescences $=4$. Ten branches per tree were scored, and their mean score was taken as the masting index for that tree. New branches were examined each year.

- Picea abies - Cones were counted in tree crowns. Only the current season cones (greenish, with scales adhering to slightly parted, often with resin drips) were included. The previous years' cones (brownish or greyish, with parted scales), at times quite abundant, were ignored. All cones visible in the $\sim 5-\mathrm{m}$ top southern section of a tree were counted. Cone numbers were ranked as follows: no cones $=0,1-5=1,6-10=2,11-20=3$ and $>20$ cones $=4$.

- Quercus robur-During the period when observations were made, acorns were already on the ground so their abundance was determined under the trees within one square metre below the southern portion of the tree crown. All litter was carefully removed from this area, and the number of cupules (a surrogate measure of the number of acorns, accounting for partial depredation) was counted and expressed as the number of acorns $/ \mathrm{m}^{2}$. The numbers were ranked as follows: no acorns $=0$, $1-5=1, \quad 6-10=2, \quad 11-20=3$, and $>20$ acorns $/$ $\mathrm{m}^{2}=4$.

To quantify the extent of leaf loss due to herbivory, we assessed the defoliation level of the sample trees mentioned above, using the procedures described by Wesołowski and
Rowiński (2006, 2008). The amount of defoliation was estimated during the seasonal peak of leaf damage, just prior to leaf replacement. The foliage loss was assessed from the ground, below the tree crown, using binoculars or a telescope. The observer compared the amount of foliage loss with an imaginary intact crown of the same tree. Quite often, the leaf damage was non-uniform; some parts of the crown were more heavily affected than others. The crown was then assessed from several points/angles and the estimated loss averaged across all parts of the crown in order to produce a composite score for a given tree. The amount of defoliation was scored as-0: (no)—leaves intact, or some leaves with small decrements (at most small holes and/or slightly damaged edges), up to $10 \%$ of the foliage missing; 1 : (slight) $>10$ and up to $\sim 25 \%$ of the foliage missing; 2 : (moderate)-between 25 and $\sim 75 \%$ of the foliage missing; or 3: (heavy) - more than $75 \%$ of the foliage missing.

Meteorological data were obtained from the nearest weather station in Białowieża village, $\sim 1 \mathrm{~km}$ from the study area (Wesołowski and Tomiałojć1997; Rowiński 2001; Wesołowski and Cholewa 2009; own unpublished data). Meteorological data have been available for the first 10 years of the study period.

\section{Data analysis}

\section{Seed production}

Except in $Q$. robur, we used size of fruit crops as a proxy of seed production. As the proportion of fruit containing sound seed tends to be higher in good years (review in Norton and Kelly 1988; Mencuccini et al. 1995; Monks and Kelly 2006), this could affect the results and the actual variation in the production of seeds could be underestimated. As we were interested in variation of the relative crop sizes and not in their absolute values (biomass/unit area) in individual years, this bias in seed production estimates is likely negligible.

We first examined how the data from the repeated sampling (30 trees/species) reflected the interyear variation in the seed crop index derived form larger samples (53-310 trees/ species) collected over wider areas. After finding that the median seed scores derived from both data sets were very strongly positively correlated $\left(r_{\mathrm{s}}=0.94-1.0\right.$ depending on tree species, $p \ll 0.001$ in each case), we concluded that the repeated samples were sufficient to characterise the variation in BNP and that they provided seed production indices representative of the wider set of conditions. Therefore, we have restricted our analyses to patterns of variation as revealed by the repeated measurements of seed production by individual trees. When a dying tree was replaced by a new individual (described above), we treated observations of the latter as a continuation of records of the former and the data were pooled to form a single series of values. As we did not know 
to what extent the fructification pattern of the replacement individuals matched that of the original ones, this measure probably somewhat increased "noise" in the data, rendering detection of patterns more difficult. In addition to scoring individual trees, we also calculated summary scores for each species. These summary metrics included yearly seed production indices for individual plots as well as for the entire local population. In phenologically dimorphic $Q$. robur (Wesołowski and Rowiński 2008), we also calculated separate seed production indices for early-leafing $(n=18)$ and late-leafing $(n=12)$ forms.

\section{Weather variables}

All species formed flower buds in a summer of one year, they blossomed in spring of the following year, and their fruits developed and matured in summer of the same year. As temperature and rains during flower bud formation, flowering time and/or during seed formation itself are known to affect their seed crop production (reviews in Matthews 1963; Barzdajn 1991; Suszka 1993, 2006; Owens 1995; Tylkowski 1999; Selås et al. 2002), we extracted values of mean monthly temperatures $\left({ }^{\circ} \mathrm{C}\right)$ and monthly rainfall $(\mathrm{mm})$ for all those periods in which temperatures and rainfall could influence the above-mentioned processes. These periods of sensitivity included June and July of the previous (flower bud formation) and current year (seed formation), as well as April and May of the current year (flowering and pollination). We also calculated values for the half-month periods corresponding to the presumed flowering seasons. Timing of flowering of individual species was set following Wesołowski and Rowiński (2006) and our own unpublished observations. To test for an effect of winter cold, we used mean temperature of the coldest day in the preceding winter (December-February).

\section{Statistical analysis}

All statistical analyses were conducted with STATISTICA 10 (StatSoft 2011). As distribution of seed production indices did not meet parametric assumptions, we employed nonparametric statistics throughout. We used medians and interquartile ranges to describe variation in seed production and repeated measures tests (Wilcoxon's matched pairs and Kendall's coefficient of concordance) to test for synchrony of seed production variation. All probability values shown are two-tailed.

\section{Results}

Population-level variation

Despite the spatial separation of the three study plots (up to $\sim 4 \mathrm{~km}$ ), the production of seeds by different tree species was highly synchronised. The concordance of year-to-year variation of the median seed crop indices ranged from 0.85 in $T$. cordata to 0.96 in $C$. betulus and P. abies (Kendall's coefficient of concordance, $n=3, d f=11, p<0.002$ in each case). Because of the high synchrony among plots, we did not use "area" as a separate variable in further analyses. We pooled the data from all plots and calculated a single-seed score index for each tree species and year.

At the population level, seed production varied substantially among years (Fig. 1). In each species, these interannual differences were significant (Friedman ANOVA $_{30,11}, \quad \chi^{2}=175.9-284.5, \quad p \ll 0.001$ in every case).

Seed production of different species varied independently of one another. There were no significant correlations between the species in the median annual seed scores (Table 1). Only seed crops of $C$. betulus and A. platanoides showed some tendency to vary in parallel $\left(r_{\mathrm{S}}=0.59, p=0.09\right)$. Seed production of the early- $(n=18)$ and late- $(n=12)$ leafing forms of $Q$. robur varied in synchrony (Kendall's coefficient of concordance of yearly medians $=0.90, p<0.05$ ), despite their largely different (up to five weeks; Wesołowski and Rowiński 2008) flowering times.

Due to the lack of interspecific synchrony, there was no complete failure for any one year (all species but $P$. abies failed in 2003), nor was there a "bonanza" year in which all species produced bumper crops simultaneously (all species but $Q$. robur reached maximum scores in 2006).

The extent of interannual variation in seed production differed among species; $A$. platanoides fructified more regularly $(\mathrm{CV}=76)$ than $P$. abies $(\mathrm{CV}=129)$ or $Q$. robur $(\mathrm{CV}=150)$-Table 2. Wind-pollinated $P$. abies and $Q$. robur tended to produce either bumper crops (score 4 ) or no seeds at all (score 0, Fig. 1), and moderate crops were observed only in two and one of 12 years, respectively (Table 2). In contrast, insect-pollinated A. platanoides and $T$. cordata produced seeds more uniformly with intermediate values found in six and eight seasons, respectively (Table 2).

All species produced abundant seed crops over 3-5 years during the 12 years of observations, but species differed greatly in number of fruitless seasons, from one crop failure in $T$. cordata to seven in $Q$. robur and $P$. abies (Table 2). The difference between proportion of poor years in $T$. cordata and the other species was significant (Fisher's exact test, $p=0.027$ ). Despite extensive searches (we observed up to 310 trees/species in some seasons), no new cones or acorns in four of seven poor years were found. Though, in $P$. abies, numerous old cones from the previous year (still containing some seeds) were found in two of the fruitless years $(2009,2012)$. In the remaining species, a minority of trees produced small amounts (score $<1$ ) of seeds even in the poor years. 

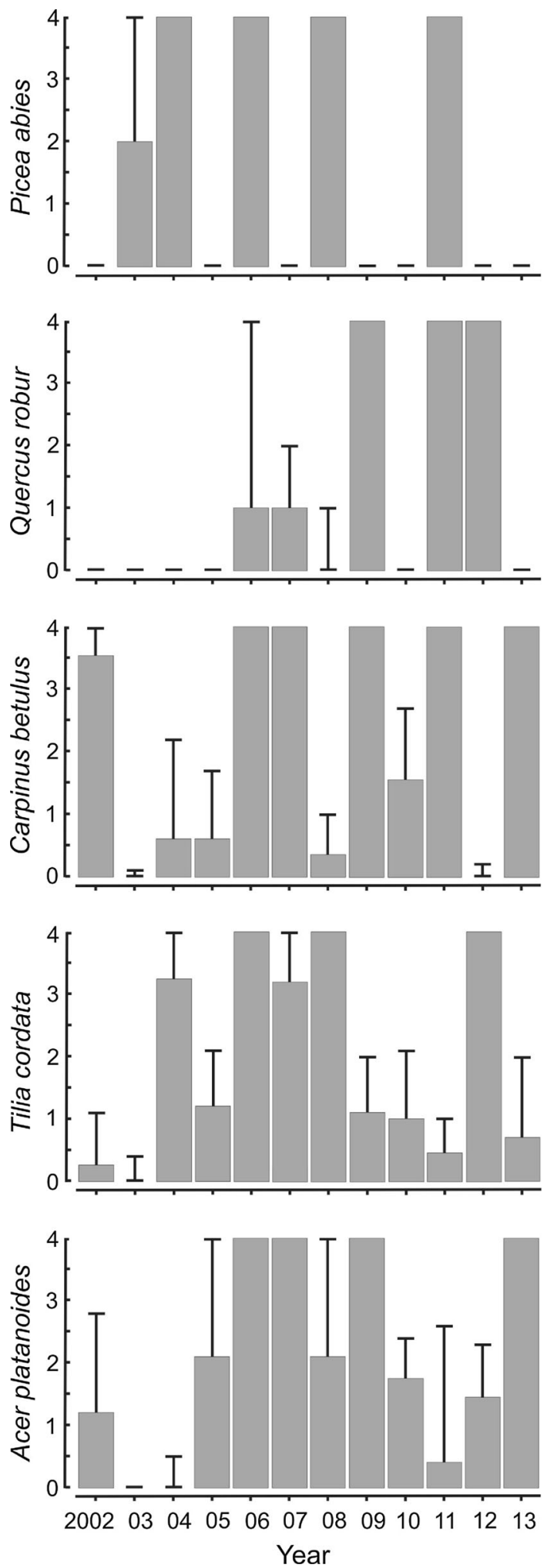

Fig. 1 Annual variation in seed production by five species of trees in BNP, 2002-2013. Median (bars) and 75 percentiles (whiskers) fructification scores of 30 trees/species are shown. The values of seed crop index varied between 0 (no seeds) and 4 (maximum score). The measurements used to calculate the indices differed between species (see "Study area and methods" for details)
Table 1 Average rank correlation coefficients (above) and their probabilities (below diagonal) of seed production by five tree species in 2002-2013 in BNP (median of annual seed crop scores were used)

\begin{tabular}{llllll}
\hline & $\begin{array}{l}\text { T. } \\
\text { cordata }\end{array}$ & $\begin{array}{l}\text { A. } \\
\text { platanoides }\end{array}$ & $\begin{array}{l}\text { C. } \\
\text { betulus }\end{array}$ & $\begin{array}{l}Q . \\
\text { robur }\end{array}$ & $\begin{array}{l}P . \\
\text { abies }\end{array}$ \\
\hline $\begin{array}{l}\text { Tilia cordata } \\
\text { Acer }\end{array}$ & 0.19 & 0.36 & -0.15 & 0.24 & 0.24 \\
$\begin{array}{c}\text { platanoides } \\
\text { Carpinus } \\
\text { betulus }\end{array}$ & 0.59 & 0.09 & 0.59 & 0.23 & -0.35 \\
$\begin{array}{l}\text { Quercus } \\
\text { robur }\end{array}$ & 0.25 & 0.26 & 0.18 & & $>0.01$ \\
$\begin{array}{c}\text { Picea abies } \\
\text { Picen }\end{array}$ & 0.25 & 0.78 & 0.52 & 0.45 & \\
\hline
\end{tabular}

Table 2 Distribution of medians of yearly seed production scores in different tree species in BNP. Coefficients of variation in annual seed production are also shown

\begin{tabular}{llllr}
\hline Species & \multicolumn{3}{l}{$N$ years with score } & CV \\
\cline { 2 - 4 } & 0 & $>0,<4$ & 4 & $(\%)$ \\
\hline Tilia cordata & 1 & 8 & 3 & 83.5 \\
Acer platanoides & 2 & 6 & 4 & 75.9 \\
Carpinus betulus & 2 & 5 & 5 & 82.2 \\
Quercus robur & 7 & 2 & 3 & 150.0 \\
Picea abies & 7 & 1 & 4 & 128.7 \\
\hline
\end{tabular}

Only P. abies exhibited a consistent pattern of alternate bumper and failure seasons, repeated every two to three years; a heavy cone production season was always followed by a poor season (Fig. 1), and the seed crop in one year tended to be negatively related to that of the previous year $\left(r_{s}=-0.54, p=0.08\right)$. In all other species, no consistent interchange of good and bad years was detectable, and copious seed could be produced in two consecutive years (Fig. 1, $r_{s}=-0.38-0.49, p=0.48-1.0$ ). There was no relationship between the crop of the 2 years prior to the current year's seed production in these species $\left(r_{s}=-0.15\right.$ to $0.18, p=0.48-1.0$ ).

Inter-individual variation

All trees produced some seeds in at least one year. Some individuals produced seeds every year (A. platanoides -5 , C. betulus-4, T. cordata-3). A few trees (A. platanoides - 5, T. cordata - 4 and Q. robur-3), however, did not produce the maximum crop (score 4) during the whole study period (Fig. 2). The number of years with bumper crops produced by the trees differed among species (Fig. 2; Kruskal-Wallis ANOVA $\left.H_{4,150}=27.5, p \ll 0.001\right) ; C$. betulus trees (median $=5$ years) produced such crops significantly more frequently than $T$. cordata (3 years) or $Q$. 


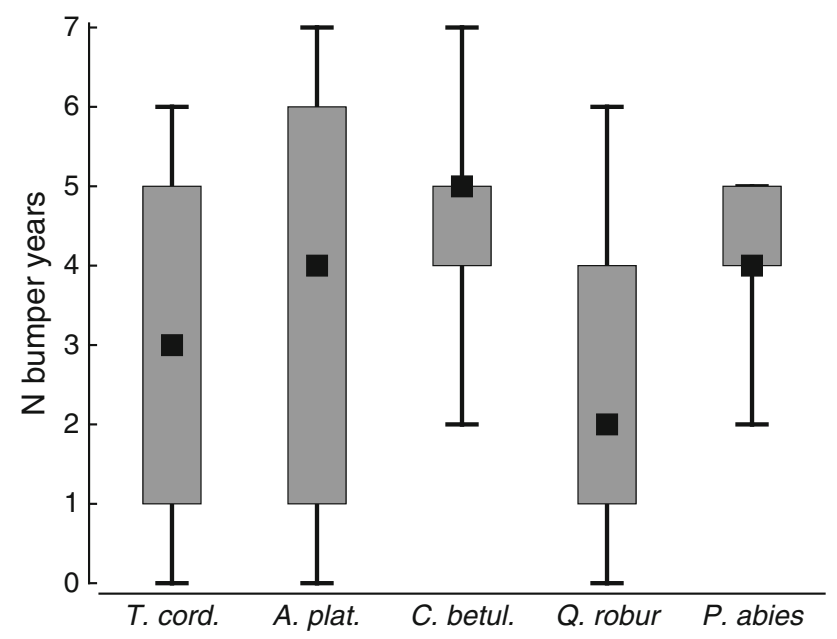

Fig. 2 The number of years when individual trees of different species produced heavy seed crops (crop index $=4$ ) in BNP. Median values (black squares), 25-75\% percentiles (boxes) and ranges (whiskers) of the number of years with bumper crops are shown

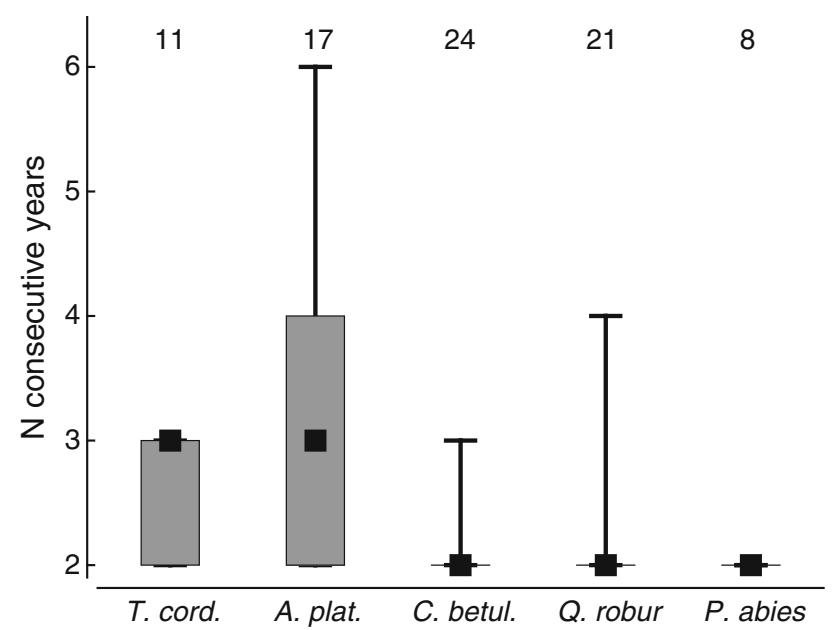

Fig. 3 The number of consecutive years in which individual trees of different species produced heavy seed crops (crop index $=4$ ) in BNP. Median values (black squares), 25-75\% percentiles (boxes) and ranges (whiskers) of the number of years with bumper crops are shown. The number of trees which produced bumper crops in the consecutive years is given at the top

robur (2 years; multiple comparisons $p=0.003$ and $<0.001$, respectively). Some trees produced copious crops in consecutive years (up to six years in sequence; Fig. 3). This was observed in over two-thirds of $C$. betulus and $Q$. robur trees, but only in eight $P$. abies trees (Fig. 3). The number of consecutive seasons with heavy crops differed significantly across species (Kruskal-Wallis's ANOVA $\left.H_{4,81}=38.2, p \ll 0.001\right)$; it was significantly higher in $A$. platanoides (median $=3$ years) than in three other species (Fig. 3; multiple comparisons $p=0.001-0.026$ ).

Interannual variation in seed production at the individual level followed the pattern visible at the population level. $T$. cordata exhibited the most uniform distribution of seed production, though even in this species the number of seasons with extreme poor or good crops exceeded the number of intermediate years (Table 3). Trees of other species showed a clear bimodal distribution of crop sizes. $P$. abies, which were most extreme in this respect, produced hardly any intermediate crops (Table 3). Moreover, $P$. abies individuals produced similar sized seed crops within a season (mean $\mathrm{CV}=10.4 \%$ ), and they varied in seed production among years in a highly coordinated fashion (Kendall's coefficient of concordance $=0.93$, Table 4), whereas individuals of other species showed higher variation in seed production within a season (mean $\mathrm{CV}=72-96 \%$ ) although their seed crops remained well synchronised among years (Kendall's coefficient of concordance $=0.53-0.86$, Table 4).

Overall, there was an inverse relationship between the within-season synchrony and among-year variability. The species ( $P$. abies and $Q$. robur) in which seed production was most synchronised (i.e. the size of seed crops was least variable) among individuals within a season showed highest fluctuations in seed production across years (high interannual variability), whereas the species ( $T$. cordata and $A$. platanoides) in which seed crops were less synchronised among individuals within a season also exhibited less variable interannual seed production at the population level (cf Tables 2, 4).

Environmental conditions and seed crop

Mean monthly temperatures $\left({ }^{\circ} \mathrm{C}\right)$ in the periods critical for flower bud formation, flowering, pollination and seed production (April-July) varied minimally across years $(\mathrm{CV}=6-13 \%$, Table 5), but rainfall was more variable $(\mathrm{CV}=25-73 \%$, Table 5). In most cases, the variation in weather variables was normally distributed (ShapiroWilk's normality test), except for April temperatures and June rainfall $(p<0.001$ and $p<0.004$, respectively), which exhibited a skewed distribution. The mean monthly temperatures or rainfall in June or July of the preceding year showed no significant relationship with seed production in the following year. Only after exclusion of 2003, when the poor seed crop could be due to defoliation by caterpillars (see below), was there a positive relationship between the previous year June temperature and seed crop of $T$. cordata the next year $\left(r_{\mathrm{s}}=0.67, p<0.05\right)$. Variation in monthly temperature or rainfall within the season did not exhibit a significant relationship with seed crop for either species. The amount of rainfall (but not temperature), however, during the flowering period in half-month intervals was negatively correlated with the seed crop in three deciduous species (Table 6). 
Table 3 Test for between-year bimodality of seed production. Significant values are in bold

Values are the mean number of years in which individual trees produced low (score $0-1$ ), medium (1.1-3.5) or high (3.6-4) seed crop. $p$ values for Wilcoxon's matched pairs test

\begin{tabular}{|c|c|c|c|c|c|c|c|c|}
\hline \multirow[t]{3}{*}{ Species } & \multicolumn{6}{|c|}{$N$ years with seed crop } & \multicolumn{2}{|c|}{$p$ value (comparison to medium years) } \\
\hline & \multicolumn{2}{|l|}{ Low } & \multicolumn{2}{|c|}{ Medium } & \multicolumn{2}{|l|}{ High } & \multirow[t]{2}{*}{ Low } & \multirow[t]{2}{*}{ High } \\
\hline & Mean & SD & Mean & SD & Mean & SD & & \\
\hline T. cordata & 5.1 & 2.30 & 3.6 & 1.54 & 3.3 & 1.93 & 0.036 & 0.563 \\
\hline A. platanoides & 5.0 & 2.74 & 3.3 & 1.17 & 3.8 & 2.54 & $\mathbf{0 . 0 3 0}$ & 0.309 \\
\hline C. betulus & 4.4 & 1.59 & 2.3 & 1.39 & 5.2 & 1.04 & $<0.001$ & $<0.001$ \\
\hline Q. robur & 8.3 & 1.64 & 1.2 & 0.83 & 2.6 & 1.59 & 0.001 & $<0.001$ \\
\hline P. abies & 6.6 & 0.62 & 0.4 & 0.67 & 4.0 & 0.79 & $<0.001$ & $<0.001$ \\
\hline
\end{tabular}

Table 4 Interannual variation in seed production by individual trees ( $n=30$ /species) as well as means of yearly coefficients of variation $(\%)$ of in different tree species

\begin{tabular}{llll}
\hline Species & $\begin{array}{l}\text { Kendall's coefficient } \\
\text { of concordance }\end{array}$ & $P$ & Mean CV \\
\hline T. cordata & 0.53 & $\ll 0.001$ & 82.5 \\
A. platanoides & 0.59 & $\ll 0.001$ & 96.2 \\
C. betulus & 0.86 & $\ll 0.001$ & 76.5 \\
Q. robur & 0.74 & $\ll 0.001$ & 72.4 \\
$P$. abies & 0.93 & $\ll 0.0015$ & 10.4 \\
\hline
\end{tabular}

Table 5 Mean temperatures and rainfall in the months critical for seed production and their interannual variation in BNP

\begin{tabular}{lccrllll}
\hline Month & \multicolumn{2}{l}{ Temperature $\left({ }^{\circ} \mathrm{C}\right)$} & & \multicolumn{3}{l}{ Rainfall $(\mathrm{mm})$} \\
\cline { 2 - 3 } \cline { 7 - 8 } & Mean & SD & CV & & Mean & SD & CV \\
\hline April & 8.4 & 0.5 & 6.7 & & 27.9 & 20.3 & 72.8 \\
May & 14.0 & 1.8 & 12.6 & & 77.1 & 19.2 & 24.9 \\
June & 17.4 & 1.1 & 6.2 & & 86.5 & 50.7 & 58.6 \\
July & 20.0 & 1.6 & 8.2 & & 89.9 & 56.3 & 62.7 \\
\hline
\end{tabular}

Table 6 Relationship between mean temperature and rainfall in the flowering period and median scores of seed production of five tree species in BNP

\begin{tabular}{|c|c|c|c|c|c|}
\hline \multirow[t]{2}{*}{ Species } & \multirow[t]{2}{*}{ Flowering period } & \multicolumn{2}{|c|}{$\begin{array}{l}\text { Mean temp } \\
\left({ }^{\circ} \mathrm{C}\right)\end{array}$} & \multicolumn{2}{|c|}{ Rainfall (mm) } \\
\hline & & $r_{s}$ & $p$ & $r_{s}$ & $p$ \\
\hline T. cordata & June, second half & 0.16 & 0.650 & -0.07 & 0.854 \\
\hline A. platanoides & April, second half & -0.30 & 0.406 & -0.64 & 0.045 \\
\hline C. betulus & April, second half & 0.20 & 0.578 & -0.76 & 0.011 \\
\hline Q. robur & April, second half & 0.08 & 0.821 & -0.69 & 0.028 \\
\hline P. abies & May, first half & -0.01 & 0.985 & -0.09 & 0.811 \\
\hline
\end{tabular}

Winter cold did not seem to affect seed production. Only in $C$. betulus was there some negative, but non-significant relationship between the mean temperature of the coldest winter day and seed crop $\left(r_{s}=-0.50, p=0.141\right)$. Though, even in this case, the second coldest winter $\left(-23.3{ }^{\circ} \mathrm{C}\right)$ was followed by a bumper crop the next autumn.

Folivorous caterpillars, 84-98\% of them winter moth Operophtera brumata (L.), Geometridae (Wesołowski and Rowiński 2008, 2014), caused measurable leaf loss only in 2002-2005 (Fig. 4). In all subsequent years, the defoliation level of all trees was negligible (the defoliation scores amounted to zero). Thus, defoliation could have only had a detrimental effect on seed production in a few seasons. The heaviest defoliation of all deciduous species occurred in 2003 (Fig. 4). It corresponded with very low seed production that year (Fig. 1) and only meagre seed production in 2004 in all species but T. cordata (Fig. 1). Of note, however, is the fact that even though $C$. betulus was heavily defoliated already in 2002 (Fig. 4), the trees of this species produced abundant seeds in that year (Fig. 1). In 2003, heavy defoliation affected only "early-" leafing individuals of Q. robur (Wesołowski and Rowiński 2008), but neither phenological form produced acorns that year.

\section{Discussion}

Observations of seed production in five tree species gathered over 12 years in an old-growth primeval forest reveal that species produce highly variable seed crops among years, ranging from no seeds in some seasons to bumper crops in others. With the possible exception of $C$. betulus and A. platanoides, the seed crops of different species did not covary. This pattern of non-synchrony among species generally supports earlier findings in BNP (Falińska 1971; Pucek et al. 1993). The only exception was that pertaining to Pucek et al.'s (1993) work where we did not find synchronous annual variation in seed production among $Q$. robur and $C$. betulus and $A$. platanoides. The discrepancy could be due to methodological differences; Pucek et al. (1993) used annual purchases of acorns by local forestry authorities as a relative measure of variation in $Q$. robur seed production rather than direct observation. Intraspecifically, seed production by individual trees was highly 

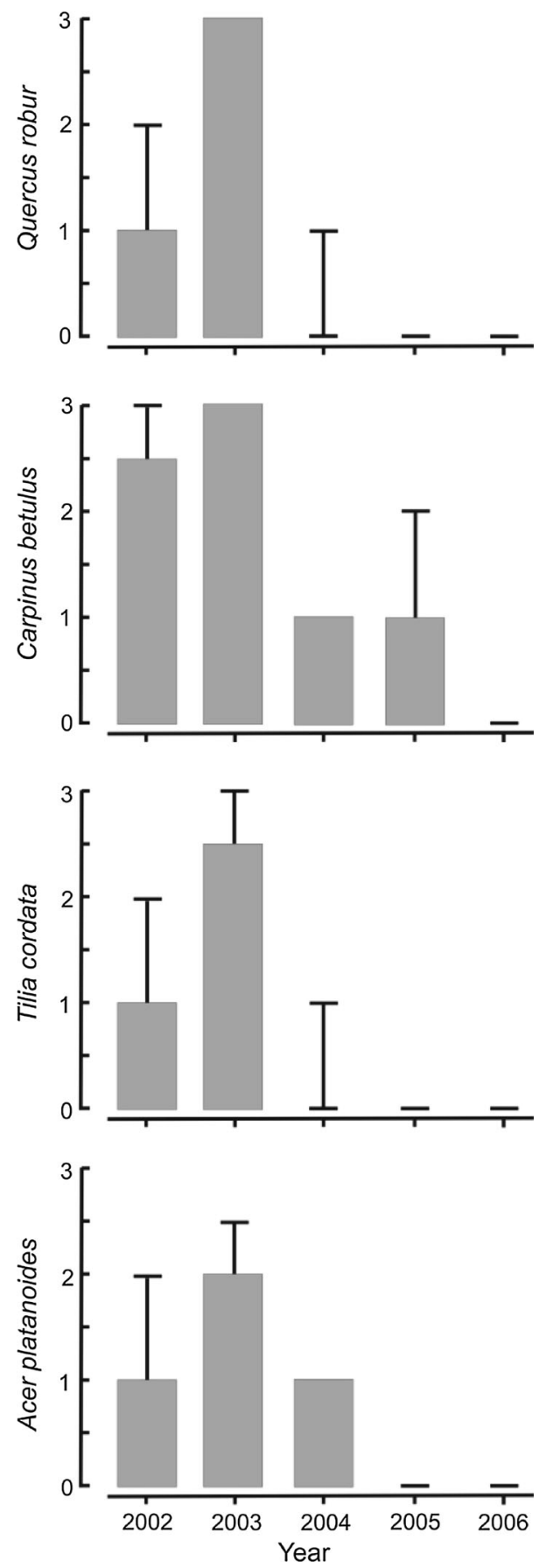

Fig. 4 Annual variation in defoliation scores of deciduous trees species in BNP, 2002-2006. Median (bars) and 75 percentiles (whiskers) of the defoliation index of 30 trees/species are shown. Defoliation scores varied between 0 (below $10 \%$ of foliage missing) to 3 (heavy, $>75 \%$ of foliage missing; for more information see "Study area and methods")

synchronised in time and space. Seed crops covaried in areas several kilometres apart. This suggests that trees in all places were similarly affected by varying extrinsic factors, but that each species responded to the environmental cues in a species-specific fashion. Such patterns of variation seem to be characteristic of multispecies temperate forests like those found in Japan (Shibata et al. 2002), England (Gurnell 1993) or the USA (Liebhold et al. 2004).

Annual variation in seed production by different species was not proportional to the variation in environmental factors (temperature and rainfall), which suggests the pattern of fruiting could not result from "resource matching" by trees (Kleb 1904, in Norton and Kelly 1988). Amplitudes of inter-year fluctuations in temperature and rainfall were much smaller than observed variation in seed crops. Moreover, variation in weather variables exhibited, as a rule, a normal distribution, whereas variation in crop size was most often bimodal. Even if seed production by trees, however, did not match variation in availability (weather related), adverse external events could still prevent seed production and cause synchronous population-wide reproductive failures.

Extreme weather events such as severe cold that could destroy flower buds or impede flowering were found to have disruptive effects on seed production in the tree species used in this study (Q. robur-Jones 1959; T. cordata-Pigott and Huntley 1981; A. platanoides-Kulagin and Mushinskaya 1984; P. abies-review in Selås et al. 2002). Yet, such disruptions did not seem to be a factor in BNP. Even when winter temperatures dropped below $-20{ }^{\circ} \mathrm{C}$, no visible effect on seed production the following year was observed. The only consistent relationship found was a negative correlation between rainfall amount during flowering and subsequent seed crops in C. betulus, Q. robur and A. platanoides. It is possible that precipitation both arrested aerial pollen transfer in $C$. betulus and $Q$. robur and lowered activity of insects and their efficiency of pollination in A. platanoides. This explanation is tentative at best since we did not measure flowering intensity per se. Therefore, we cannot determine whether trees produced many flowers that failed to get pollinated or were affected in some other manner. The fact that few flowers developed during rainy conditions might simply be a coincidence.

The relative decoupling of seed production by trees in BNP from environmental variation is unexpected since strong weather effects have been found in numerous other studies of these species (reviews in Matthews 1963; Barzdajn 1991; Suszka 1993, 2006; Owens 1995; Tylkowski 1999; Selås et al. 2002).

The climatic conditions faced by trees in BNP are likely more benign, and their seed production less often limited by weather extremes than those of trees growing in harsher environments. For example, Selås et al. (2002) found that abundant cone production in southern Norway required warm summer weather (June-July temperatures $>15^{\circ} \mathrm{C}$ ), in the preceding year. Summer temperatures in BNP remained above this threshold. Thus, even if high summer 
temperatures remained important for flower bud formation, their variability could not account for the interannual variation observed in BNP.

Our data indicate that defoliation by folivorous caterpillars may have detrimental effects on seed production by trees. Heavy defoliation of all deciduous tree species in 2003 in BNP coincided with a very poor seed crop that year. The caterpillars could act directly by destroying flowers/embryos, or indirectly - the cost of developing a second generation of leaves by a tree could be so large that the caterpillars negatively affected the trees' ability to produce seeds. The defoliation, however, may not be the only factor involved. On the one hand, despite heavy defoliation of $C$. betulus in 2002, trees showed an ability to produce bumper seed crops that year. On the other hand, the "late-" leafing form of $Q$. robur failed to reproduce in 2003 even though the trees were not heavily defoliated that year (Wesołowski and Rowiński 2008). The effects of defoliation on seed production have been little studied; only Jones (1959) and Gurnell (1993) even mention that defoliation of oaks (by Tortrix viridana) caterpillars could have prevented acorn production by $Q$. robur.

An ideal masting species consists of perfectly synchronous fruiting individuals that either produce large quantities of seeds or none at all. Most species studied to date, however, fall short of this ideal pattern (reviews Kelly 1994; Herrera et al. 1998; Koenig and Knops 2000; Crone et al. 2011). Several tree species of BNP did match predictions for masting species: (1) seed production varied strongly among years with bumper crops observed in some and little to no seeds in others and (2) variation among areas was highly synchronous within species. Though the species differed in the degree of this variability, $P$. abies exhibited the highest variation among years and highest synchrony among individuals (i.e. trees tended to produce either bumper crops or none at all, few intermediate crops were observed). $Q$. robur displayed a similar pattern of interannual variation and retained high synchrony among individuals despite disparate leafing phenology (early and late forms; Wesołowski and Rowiński 2008). Interannual variation in fruiting by $C$. betulus was lower than in $P$. abies or $Q$. robur but trees did exhibit a bimodal distribution in yearly seed production that was well synchronised among individuals within a season. A. platanoides and $T$. cordata, by contrast, produced seeds more uniformly, with intermediate seed crops found in six and eight seasons, respectively. Seed production of individual trees was less tightly synchronised than in the other aforementioned species. Thus, trees in BNP can be ranked along a masting—non-masting axis, from high "masting" $P$. abies, through $Q$. robur, C. betulus to low "masting" A. platanoides and $T$. cordata. This raises an important biological question of why trees living side-by-side in the same forest exhibit such different patterns of seed production? Does it follow that intermittent mass reproduction has differential benefits to each taxon?

All proposed explanations of "masting" incorporate the idea of trade-offs between growth and reproduction and between investments in current and future reproduction (reviews Kelly 1994; Herrera et al. 1998; Koenig and Knops 2000; Crone et al. 2009). In order to produce a superabundance of seeds, a tree must incur a cost; the tree, thus, must divert resources and energy from vegetative growth to the production of seed crops. Therefore, "true masting" species (sensu Kelly 1994) are predicted to reallocate resources from available reserves into seed production to produce large seed crops. This pattern should be expressed as either (1) a negative correlation between seed production in one year relative to the next and/or (2) low tree growth (measured as radial wood increment) in bumper crop years (Silvertown 1980; Sork et al. 1993; Kelly 1994; Koenig and Knops 1998, 2000; Kelly and Sork 2002; Monks and Kelly 2006). Although such correlations have been found in several species at the population level (review in Kelly and Sork 2002), including Q. robur in England (Crawley and Long 1995) and P. abies in Norway (Selås et al. 2002), the predicted relationship between reproduction and growth at the individual level (studied only in about 10 species; Monks and Kelly 2006) is not always found (Seifert and Müller-Starck 2009-P. abies, Żywiec and Zielonka 2013) or it appears not to be causally related (Knops et al. 2007). We have no data from BNP on variation in tree growth rates to check the postulated growth/reproduction trade-offs, but the predicted negative relationship between the current and the next year seed production was found only in P. abies. In this species, bumper crop years were almost always followed by poor crop years-only a few trees ever produced cones in two consecutive seasons. Other tree species did not follow this pattern-they sometimes produced bumper crops in consecutive years, and some individual trees could produce superabundant seed crops over 3-4 (up to six) consecutive seasons. These observations indicate that production of bulk seed crops did not necessarily always exhaust energetic and nutrient reserves of trees; the trees can apparently "decide" which fraction of available nutrients shall be invested in seeds. Because the trees observed in BNP were mature individuals, with crowns already reaching the main canopy, they likely could afford to invest in reproduction more than their younger counterparts (see Seifert and Müller-Starck 2009). Moreover, deciduous species studied in BNP grow in favourable conditions on rich soils and in a locally optimal habitat type (Faliński 1986), far from the limits of their respective geographic ranges, whereas $P$. abies is found in less favourable habitat 
(Faliński 1986) at or near the southern extent of its boreal range. Perhaps, these relative geographic distributions may explain the differences in fruiting patterns among species.

Hoch et al. (2013) demonstrated in C. betulus and in close relative of $Q$. robur, Quercus petraea (Mattuschka) Liebl.), that fruiting was independent from stored carbon reserves, and their seed production relied entirely on carbon from current photoassimilates. Therefore, if resource accumulation is indeed required for mast seeding (Kelly 1994, Koenig and Knops, 1998), it is likely that, contrary to some herbaceous plants (Crone et al. 2009), resources other than carbohydrates (e.g. $\mathrm{N}$ or $\mathrm{P}$ ) could be limiting. However, even if seeds are not produced from stored reserves, the tree has still to decide how to allocate the current assimilates between vegetative growth, seeds and formation of the next year's flower buds. In all tree species studied in BNP, the latter are set on the same branches, alongside with the fruits, so any physiological mechanism inhibiting initiation of flower buds by developing seeds (e.g. Packham and Hilton, 2002) would automatically result in alternate mast and fruitless years. Such simple feed-back mechanism, though, could work only in P. abies; Tiren (1935, in Matthews 1963) showed that in this species flower bud formation reduces the potential foliage producing buds in that season, whereby the possibilities of flower bud formation are reduced in the next year. In the deciduous species, though, the means of seed production control would have apparently been more complicated.

The purported adaptive benefits of irregular mass reproduction stem from the "economies of scale" (Norton and Kelly 1988); trees should increase relative fitness by producing occasional large episodic seed crops rather than regular smaller crops because of more efficient pollination, seed predator satiation, fruit dispersal or any combination thereof (see reviews in Kelly 1994; Koenig et al. 1994; Herrera, et al. 1998; Koenig and Knops 2000; Kelly and Sork 2002). As no tree studied in BNP produced fleshy fruits to be dispersed by frugivores, all seed dispersal by vertebrates thus constituted a by-product of seed predators' activities. Therefore, in BNP, the "dispersal" benefits constitute just a subset of a broader "predator satiation" phenomenon and will be discussed along with it.

The relationship between rainfall during the flowering period and subsequent seed production suggests that pollen availability might limit seed production-at least in some seasons. The "pollination efficiency" hypothesis states that masting should be selected for in species that can achieve greater pollination efficiency when simultaneously mass flowering (Norton and Kelly 1988). This fitness advantage should be more pronounced in wind-pollinated species rather than in animal-pollinated species since a mass display of flowers in the latter could overwhelm the capacity of pollinators (Sork 1993; Kelly 1994; Herrera et al. 1998;
Koenig et al. 2003; and references therein). Empirical observations confirm this postulate. On average, windpollinated species tend to show higher inter-year variability in seed production than animal-pollinated ones (reviews of Herrera et al. 1998; Kelly and Sork 2002). Data from BNP support these observations; wind-pollinated $P$. abies, $Q$. robur and $C$. betulus exhibit more interannual variability and greater within-season synchrony than insect-pollinated A. platanoides and T. cordata.

Apart from synchronous production, availability of pollen shall also depend on the density of conspecifics reproducing in the neighbourhood-trees growing in dense conspecific patches would be less often limited by pollen supply than scarcely distributed ones. Hence, pressure on synchronous flowering should be less in the former than the latter (Nilsson 1985; Nilsson and Wästljung 1987; Norton and Kelly 1988; Knapp et al. 2001; review in Kelly et al. 2001). This could possibly explain the more synchronised reproduction in $P$. abies and $Q$. robur than in $C$. betulus in BNP. $P$. abies and $Q$. robur occur in BNP oak-hornbeam habitat as isolated trees, whereas $C$. betulus is the most numerous tree, forming a continuous canopy over much of the park (Wesołowski 1996; Rowiński 2001). Failure of flowering of a few neighbouring trees would likely have no detectable effect in $C$. betulus, while it could limit pollination in $P$. abies and $Q$. robur. The relative scarcity of $Q$. robur was enhanced by its phenological diversificationflowering periods of the early and late individuals rarely overlapped (Wesołowski and Rowiński 2006, 2008).

We were unable to gather observations on the fate of seeds, so we are, thus, unable to address the "predator satiation" hypothesis directly. Though, it is known thatsimilar to other areas (reviews in Yang et al. 2008, 2010) pulses of superabundant seeds in BNP trigger shifts in diet and reproduction of numerous avian and mammalian seed eaters, and these pulses likely have far-reaching cascading effects (Pucek et al. 1993; Okarma et al. 1995; Zalewski and Jędrzejewski 2006; Wesołowski et al. 2009; Tomiałojć 2012). The bumper crops engage not only sedentary consumers (which could be eventually satiated), but also attract highly mobile nomadic avian seed eaters (such as e.g. Loxia curvirostra L.) that increase the overall predation and costs of masting (Nilsson 1985; Nilsson and Wästljung1987; Kelly et al. 2001). In contrast, however, to insect seed predators that only kill seeds, vertebrate predators in European forests are often simultaneously seed consumers and seed dispersers (Nilsson 1985; Nilsson and Wästljung 1987). Thus, their increased attraction to masting areas increases seed destruction but also increases the proportion of seeds dispersed and/or distances of seed dispersal ("animal dispersal" hypothesis, Kelly 1994). Thus, increased seed consumption may be offset by the dispersal benefits for trees. 
In BNP, trees have only a few common seed predators. Seeds of different species are likely attacked by largely disparate sets of insect predators (e.g. Turgeon et al. 1994; Stocki et al. 2007). Also, the assemblage of vertebrate seed consumers varies according to tree species. For example, acorns are consumed mostly by Garrulus glandarius (L.) and mammals up to the size of Bison bonasus (L.) (Krasińska and Krasiński 2007), whereas P. abies seed cones are extracted mostly by several bird species and Sciurus vulgaris (L.) (T. Wesołowski and P. Rowiński, unpublished observations). Thus, each tree species in BNP most probably has to cope with a unique set of predators, which may differentiate relative benefits of masting. This is probably why, in contrast to some other places (e.g. dipterocarp forests, review in Appanah, 1993; four Carpinus species in Japan, Shibata et al. 1998), different tree species in BNP produce bumper crops largely independent of one another.

In sum, a large proportion of seed crop variability, especially the occurrence of synchronous bumper crops, of trees in BNP is likely not due to abiotic (weather related) or biotic (defoliating caterpillars) extrinsic forcing. Deciduous trees have the ability to fruit copiously in consecutive seasons, demonstrating that there is not necessarily an energetic trade-off between reproduction and growth, nor are individuals constrained to non-reproduction due to resource depletion following a bumper crop season. This indicates that trees may have the ability to "decide" on when and how intensively to invest in reproduction; in this case, trees opted for bumper crops in some seasons and non-reproduction in others. Identifying environmental cues used in this "decision-making" process, in combination with physiological mechanisms by which such "decisions" are arrived at, should be the goal of future work. Our data suggest that trees in BNP could be under selection to enhance reproductive variation, i.e. trees may be selecting for the ability to mast (reviews Kelly 1994; Herrera et al. 1998; Koenig and Knops 2000, 2005; Kelly and Sork 2002).

Acknowledgments We heartily thank M. Dziedzic i J. Hankiewicz for their participation in the field work. Linguistic help and comments of E. Walters and R. Broughton are also appreciated. The final analysis was supported by an internal grant from the Faculty of Biological Sciences, Wrocław University (to TW).

Open Access This article is distributed under the terms of the Creative Commons Attribution License which permits any use, distribution, and reproduction in any medium, provided the original author(s) and the source are credited.

\section{References}

Appanah S (1993) Mass flowering of dipterocarp forests in the aseasonal tropics. J Biosci 18:457-474
Baker JR (1938) The evolution of breeding seasons. In: de Beer GR (ed) Evolution. Essays on aspects of evolutionary biology. Clarendon Press, Oxford, pp 161-177

Barzdajn W (1991) Generative reproduction. In: Białobok S (ed) Lipy Tilia cordata Mill., Tilia platyphyllos Scop. Instytut Dendrologii PAN, Poznań, pp 249-263 (in Polish, English summary)

Crawley MJ, Long CR (1995) Alternate bearing, predator satiation and seedling recruitment in Quercus robur L. J Ecol 83:683-696

Crone EE, Miller E, Sala A (2009) How do plants know when other plants are flowering? Resource depletion, pollen limitation and mast-seeding in a perennial wildflower. Ecol Lett 12:1119-1126

Crone EE, McIntyre EJB, Brodie J (2011) What defines mast seeding? Spatio-temporal patterns of cone production by whitebark pine. J Ecol 99:438-444

Falińska K (1971) An estimate of diaspore production in the ecosystem of a mixed oak-hornbeam forest (Querco-Crapinetum) in the Białowieża National Park. Ekol Pol 29:525-561

Faliński JB (1986) Vegetation dynamics in temperate forests (ecological studies in Białowieża forest). W Junk, Dordrecht

Faliński JB (1991) Le Parc national de Bialowieza et le systeme intégral des espaces protégés en Pologne. Rev For Franç 43:190-206

Faliński JB (2001) Phytophenological atlas of the forest communities and species of Białowieża. Phytocenosis NS 13:1-76

Gurnell J (1993) Tree seed production and food conditions for rodents in an oak wood in Southern England. Forestry 66:291-315

Herrera CM, Jordano P, Guitián J, Traveset A (1998) Annual variability in seed production by woody plants and the masting concept: reassessment of principles and relationship to pollination and seed dispersal. Am Nat 152:576-594

Hoch G, Siegwolf RTW, Keel SG, Körner C, Han QM (2013) Fruit production in three masting tree species does not rely on stored carbon reserves. Oecologia 171:653-662

Janzen DH (1971) Seed predation by animals. Ann Rev Ecol Syst 2:465-492

Jędrzejewska B, Jędrzejewski W, Bunevich AN, Miłkowski L, Krasiński ZA (1997) Factors shaping population densities and increase rates of ungulates in Białowieża Primeval Forest (Poland and Belarus) in the 19th and 20th centuries. Acta Theriol 42:399-451

Jones EW (1959) Biological flora of the British Isles. Quercus L. J Ecol 47:169-222

Kelly D (1994) The evolutionary ecology of mast seeding. TREE 9:465-470

Kelly D, Sork VL (2002) Mast seeding in perennial plants: why, how, where? Ann Rev Ecol Syst 33:427-447

Kelly D, Hart DE, Allen RB (2001) Evaluating the wind pollination benefits of mast seeding. Ecology 82:117-126

Knapp EE, Goedde MA, Rice KJ (2001) Pollen-limited reproduction in blue oak: implications for wind pollination in fragmented populations. Oecologia 128:48-55

Knops JMH, Koenig WD, Carmen W (2007) A negative correlation between growth and reproduction does not imply a tradeoff between growth and reproduction in California oaks. Proc Natl Acad Sci 104:16982-16985

Koenig WD, Knops JMH (1998) Scale of mast-seeding and tree-ring growth. Nature 396:225-226

Koenig WD, Knops JMH (2000) Patterns of annual seed production by Northern Hemisphere trees: a global perspective. Am Nat 155:59-69

Koenig WD, Knops JMH, Carmen WJ, Stanback MT, Mumme RL (1994) Estimating acorn crops using visual surveys. Can J For Res 24:2105-2112

Koenig WD, Kelly D, Sork VL, Duncan RP, Elkinton JS (2003) Dissecting components of population-level variation in seed production and the evolution of masting behavior. Oikos 102:581-591 
Krasińska M, Krasiński Z (2007) European bison-the nature monograph. Mammal Research Institute, Białowieża

Kulagin YuZ, Mushinskaya NI (1984) Critical periods in the seed reproduction of the Norway Maple Acer platanoides. Ekologiya (Moscow) 3:12-16

Lack D (1965) Evolutionary ecology. J Appl Ecol 2:247-255

Liebhold A, Sork V, Peltonen M, Koenig W, Bjornstad ON (2004) Within-population spatial synchrony in mast seeding of North American oaks. Oikos 104:156-164

Lugo AE, Zimmerman JK (2000) Ecological life histories In: Vozzo JA (ed) Tropical tree seed manual. USDA Forest Service, Agricultural Handbook Number 721, Washington, pp 191-213

Matthews JD (1963) Factors affecting the production of seed by forest trees. For Abstr 24:I-XIII

Maziarz M, Wesołowski T (2010) Timing of breeding and nestling diet of Wood Warbler Phylloscopus sibilatrix in relation to changing food supply. Bird Study 57:540-552

Mencuccini M, Piussi P, Sulli AZ (1995) Thirty years of seed production in a subalpine Norway spruce forest: patterns of temporal and spatial variation. For Ecol Manag 76:109-125

Monks A, Kelly D (2006) Testing the resource-matching hypothesis in the mast seeding tree Nothofagus truncata (Fagaceae). Austral Ecol 31:366-375

Niechoda T, Korbel J (2011) Puszczańskie olbrzymy. Towarzystwo Ochrony Krajobrazu, Białowieża

Nilsson SG (1985) Ecological and evolutionary interactions between reproduction of beech Fagus sylvatica and seed eating animals. Oikos 44:157-164

Nilsson SG, Wästljung U (1987) Seed predation and cross-pollination in mast-seeding beech (Fagus sylvatica) patches. Ecology 68:260-265

Norton DA, Kelly D (1988) Mast seeding over 33 years by Dacrydium cupressinum Lamb. (rimu) (Podocarpaceae) in New Zealand: the importance of economies of scale. Funct Ecol 2:399-408

Okarma H, Jędrzejewska B, Jędrzejewski W, Krasiński ZA, Miłkowski L (1995) The roles of predation, snow cover, acorn crop, and man-related factors on ungulate mortality in Białowieża Primeval Forest, Poland. Acta Theriol 40:197-217

Owens JN (1995) Constraints to seed production: temperate and tropical forest trees. Tree Physiol 15:477-484

Packham JR, Hilton GM (2002) Inter- and intra-site variation in the fruiting of common beech (Fagus sylvatica L.) over a twentytwo year period (1980-2001). Arboric J 26:1-22

Pigott CD, Huntley JP (1981) Factors controlling the distribution of Tilia cordata at the northern limits of its geographical range. III. Nature and causes of seed sterility. New Phytol 87: 817-839

Pucek Z, Jędrzejewski W, Jędrzejewska B, Pucek M (1993) Rodent population dynamics in a primeval deciduous forest (Białowieża National Park) in relation to weather, seed crop, and predation. Acta Theriol 38:199-232

Rowiński P (2001) Timing of breeding of Nuthatch Sitta europaea in relation to food resources in a natural forest. Dissertation, SGGW, Warsaw (in Polish)

Seifert T, Müller-Starck G (2009) Impacts of fructification on biomass production and correlated genetic effects in Norway spruce (Picea abies [L.] Karst.) Eur. J For Res 128:155-169

Selås V, Piovesan G, Adams JM, Bernabei M (2002) Climatic factors controlling reproduction and growth of Norway spruce in southern Norway. Can J For Res 32:217-225

Shibata M, Tanaka H, Nakashizuka T (1998) Causes and consequences of mast seed production of four co-occurring Carpinus species in Japan. Ecology 79:54-64

Shibata $M$, Tanaka $H$, Iida $S$, Abe $S$, Masaki $T$, Niiyama $K$, Nakshizuka T (2002) Synchronized annual seed production by
16 principal tree species in a temperate deciduous forest, Japan. Ecology 83:1727-1742

Silvertown JW (1980) The evolutionary ecology of mast seeding in trees. Biol J Linn Soc 14:235-250

Sork VL (1993) Evolutionary ecology of mast-seeding in temperate and tropical oaks (Quercus spp.). Vegetatio 107(108):133-147

Sork VL, Bramble J, Sexton O (1993) Ecology of mast-fruiting in three species of North American deciduous oaks. Ecology 74:528-541

StatSoft, Inc. (2011) STATISTICA (data analysis software system), version 10. www.statsoft.com

Stocki J, Kinelski S, Dzwonkowski R (2007) Szkodniki nasion o owoców drzew i krzewów leśnych. Multico, Warszawa

Stutchbury BJM, Morton SE (2001) Behavioral ecology of tropical birds. Academic Press, London

Suszka B (1993) Generative reproduction. In: Bugała W (ed) Grab zwyczajny Carpinus betulus L. Instytut Dendrologii PAN, Poznań, pp 97-134 (in Polish, English summary)

Suszka B (2006) Generative propagation. In: Bugała W (ed) Dęby [Quercus robur L. i Q. petraea (Matt.) Liebl.]. Instytut Dendrologii PAN, Poznań pp 305-389 [In Polish, English summary]

Thomas PA, Packham JR (2007) Ecology of woodlands and forests. Cambridge University Press, Cambridge

Tiren L (1935) Om granens kottsättning, dess periodicitet och samband med temperatur och nederbörd. Meddelandedn från Statens Skogsfärsöksanstalt Stockholm 28:413-424

Tomiałojć L (2012) Reproduction and population dynamics of Hawfinches Coccothraustes coccothraustes in the primeval forest of Białowieża National Park (NE Poland). Acta Ornithol 47:63-78

Tomiałojć L, Wesołowski T (1990) Bird communities of the primeval temperate forest of Białowieża, Poland. In: Keast A (ed) Biogeography and ecology of forest bird communities. Academic Publishing, The Hague, pp 141-165

Tomiałojć L, Wesołowski T (2004) Diversity of the Białowieża Forest avifauna in space and time. J Ornithol 145:81-92

Tomiałojć L, Wesołowski T, Walankiewicz W (1984) Breeding bird community of a primaeval temperate forest (Białowieża National Park, Poland). Acta Ornithol 20:241-310

Turgeon JJ, Roques A, de Groot P (1994) Insect fauna of coniferous seed cones: diversity, host plant interactions, and management. Ann Rev Entomol 39:179-212

Tylkowski T (1999) Generative propagation In: Bugała W (ed) Klony: Acer campestre L., Acer platanoides L., Acer pseudoplatanus L. Sorus, Poznań, pp 199-227 (In Polish, English summary)

Vozzo JA (ed) (2000) Tropical tree seed manual. USDA Forest Service, Agricultural Handbook Number 721, Washington

Wesołowski T (1983) The breeding ecology and behaviour of Wrens Troglodytes troglodytes living under primaeval and secondary conditions. Ibis 125:499-515

Wesołowski T (1996) Natural nest sites of Marsh Tits Parus palustris in a primaeval forest (Białowieża National Park, Poland). Die Vogelwarte 38:235-249

Wesołowski T (2007) Primeval conditions-what can we learn from them? Ibis, suppl. 2(149):64-77

Wesołowski T (2012) "Lifespan" of non-excavated holes in a primeval temperate forest: a 30 year study. Biol Conserv 153:118-126

Wesołowski T, Cholewa M (2009) Climate variation and birds' breeding seasons in a primeval temperate forest. Climate Res 38:199-208

Wesołowski T, Rowiński P (2006) Timing of bud burst and tree-leaf development in a multispecies temperate forest. For Ecol Manag 237:387-393 
Wesołowski T, Rowiński P (2008) Late leaf development in pedunculate oak (Quercus robur): an antiherbivore defence? Scandin J For Res 23:386-394

Wesołowski T, Rowiński P (2014) Do Blue Tits Cyanistes caeruleus synchronise reproduction with caterpillar peaks in a primeval forest? Bird Study 61:231-245

Wesołowski T, Tomiałojć L (1997) Breeding bird dynamics in a primaeval temperate forest: long-term trends in Białowieża National Park (Poland). Ecography 20:432-453

Wesołowski T, Rowiński P, Maziarz M (2009) Wood Warbler Phylloscopus sibilatrix: a nomadic insectivore in search of safe breeding grounds? Bird Study 56:26-33

Yang LH, Bastow JL, Spence KO, Wright AN (2008) What can we learn from resource pulses? Ecology 89:621-634

Yang LH, Edwards KF, Byrnes JE, Bastow JL, Wright AN, Spence KO (2010) A meta-analysis of resource pulse-consumer interactions. Ecol Monogr 80:125-151
Zackrisson O, Nilsson MC, Jaderlund A, Wardle DA (1999) Nutritional effects of seed fall during mast years in boreal forest. Oikos 84:17-26

Zalewski A, Jędrzejewski W (2006) Spatial organisation and dynamics of the pine marten Martes martes population in Białowieża Forest (E Poland) compared with other European woodlands. Ecography 29:31-43

Żywiec M, Zielonka T (2013) Does a heavy fruit crop reduce the tree ring increment? Results from a 12-year study in a subalpine zone. Trees 27:1365-1373

Żywiec M, Holeksa J, Ledwoń M (2012) Population and individual level of masting in a fleshy-fruited tree. Plant Ecol 213: 993-1002 